\title{
Desospitalização Humanizada
}

Paula R de Gan Rossi, Fabrizzio Batista G. L. Souza, José Martins de Siqueira, Sandra O. Guaré

Introdução: O trabalho discorre sobre os impactos assistenciais e gerenciais da implantação de um modelo de desospitalização humanizada. Durante um ano, mensuramos indicadores para registrar os resultados da aplicação desse processo, baseado na construção e utilização de protocolos.

Desenvolvimento: $O$ trabalho inicia na alta segura, seguindo um protocolo desenvolvido no serviço que prevê a identificação do local de residência do paciente de maneira visualmente rápida e possibilidade de inclusão deste na assistência domiciliar ou outro equipamento da rede.

Segue-se a identificação do objetivo terapêutico, que no modelo de hospital dia transferido para o espaço domiciliar prevê a "medicação em casa", liberando assim, o paciente precocemente para, por exemplo, término de antibioticoterapia, controle de anticoagulação, entre outros, no domicílio, bem como o cuidado paliativo. (foto 1 )

O impacto desse processo permitiu ao pronto atendimento uma queda na taxa de ocupação (paciente internado fora do leito - foto 2) de $250 \%$ para menos de 70\%, reduzindo queixas, desassistência e

principalmente, resgatando a dignidade e humanização do cuidado. O modelo desenvolvido não trabalha apenas no paciente tratável/reabilitável, mas também ampliou a possibilidade de um olhar mais aprofundado, diferenciado e humanizado no paciente portador de moléstias sem possibilidades de cura, fortalecendo o núcleo técnico científico de cuidado paliativo, seja ele no momento de fim de vida ou não, influenciando até mesmo doação de órgãos/tecidos em parceria da assistência domiciliar e a comissão intra-hospitalar de doação de órgãos e tecidos para transplante (cihdott).

Conclusão: Toda essa construção mostrou a necessidade da $A D$, enquanto modelo de desospitalização precoce, estar diretamente ligada a grupos estratégicos, se não todos, para a qualificação e fidelização do cuidado, como gestora do cuidado, da entrada à saída do hospital, e ainda na inserção na rede assistencial do território, como uma grande balsa nas múltiplas travessias que são as transições de cuidados. O paciente (e seus familiares/cuidadores) se sente $(\mathrm{m})$ assistido(s) mesmo após a saída do ambiente hospitalar, melhorando a qualidade, segurança e humanização do processo de alta. (Figs. 1, 2 e 3) APROVAÇÃO (SAU)

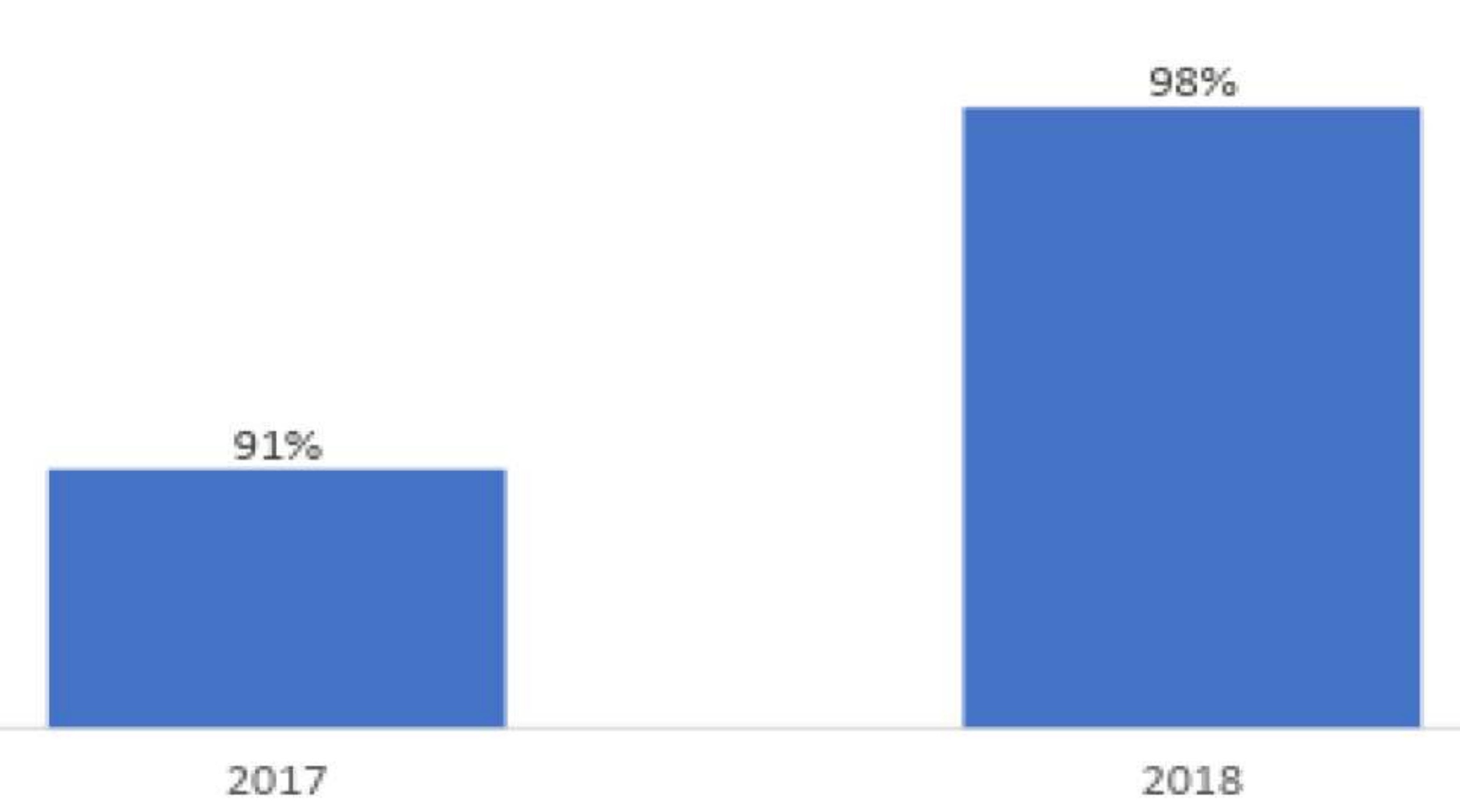

TAXA OCUPAÇÃO

घ2017 $\quad 2018$
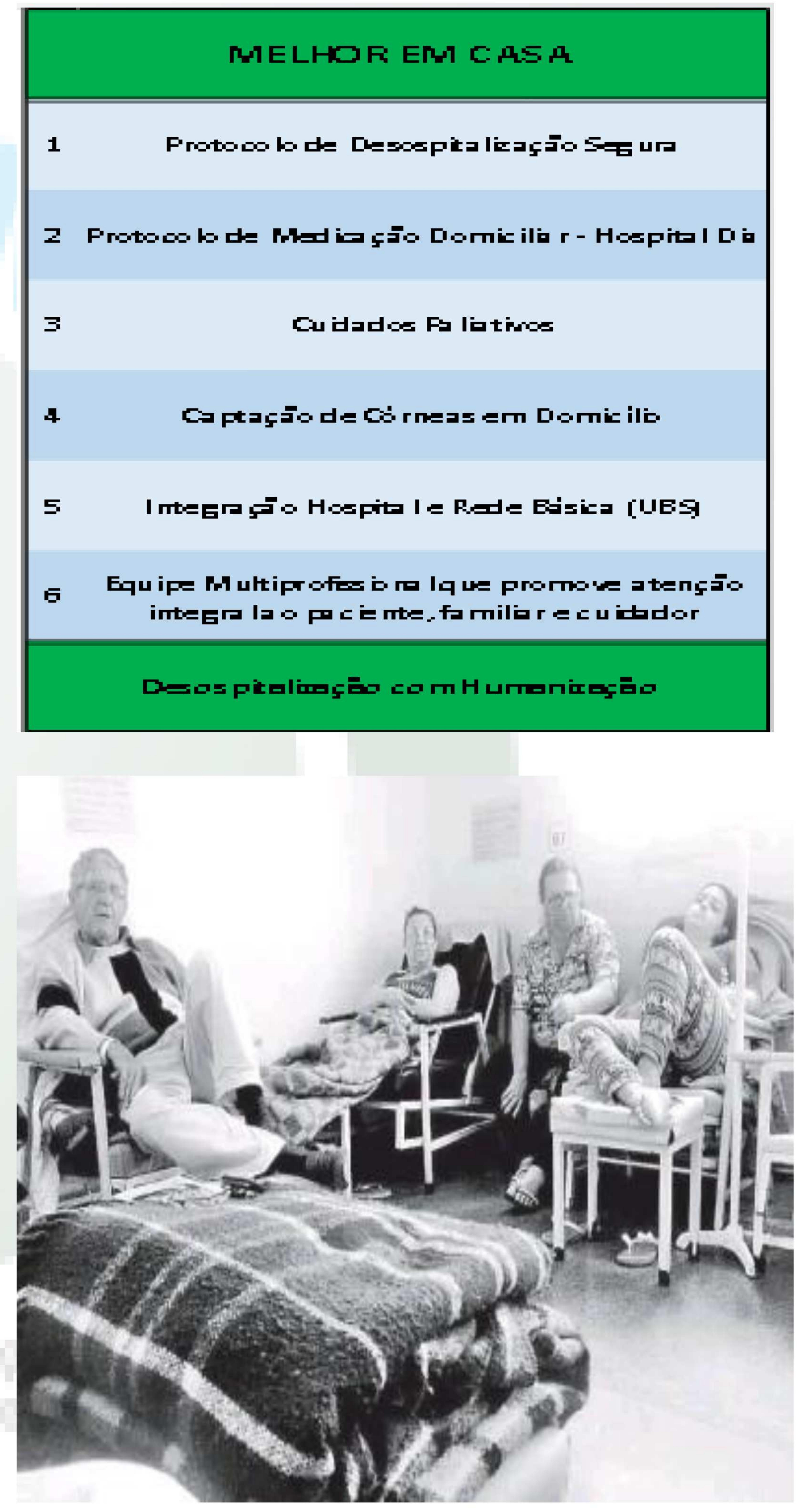